\title{
Avaliação do impacto da epizootia de Febre Amarela sobre as populações de primatas não humanos nas unidades de conservação do Rio Grande do Sul, Brasil
}

\author{
Marcos de Souza Fialho ${ }^{1 *}$ \\ Rodrigo Cambará Printes ${ }^{2}$ \\ Marco Antônio Barreto de Almeida ${ }^{3}$ \\ Plautino de Oliveira Laroque ${ }^{1}$ \\ Edmilson dos Santos $^{3}$ \\ Leandro Jerusalinsky ${ }^{1}$ \\ ${ }^{1}$ Centro Nacional de Pesquisa e Conservação de Primatas Brasileiros \\ Instituto Chico Mendes de Conservação da Biodiversidade, Ministério do Meio Ambiente \\ Praça Antenor Navarro, 5, Varadouro, CEP 58010-480, João Pessoa - PB, Brasil \\ ${ }^{2}$ Universidade Estadual do Rio Grande do Sul, Campus II, Laboratório de Gestão Ambiental e \\ Negociação de Conflitos, São Francisco de Paula - RS, Brasil \\ ${ }^{3}$ Núcleo de Vigilância dos Riscos e Agravos Ambientais Biológicos \\ Divisão de Vigilância Ambiental em Saúde, Centro Estadual de Vigilância em Saúde \\ Porto Alegre - RS, Brasil \\ *Autor para correspondência \\ marcos.fialho@icmbio.gov.br
}

\section{Resumo}

A Febre Amarela (FA) é uma doença infecciosa aguda. No Brasil, a FA tem caráter sazonal, ocorrendo frequentemente entre os meses de dezembro a abril, quando fatores ambientais propiciam o aumento da abundância dos vetores. Há diversos relatos sobre a mortalidade de primatas devido à FA, em especial os do gênero Alouatta, mas há escassa informação disponível para verificar e quantificar os danos causados às populações de primatas por eventos desta natureza. O presente estudo busca avaliar o impacto do surto de FA ocorrido entre 2008 e 2009 sobre as populações de primatas nas unidades de conservação (UC) do Estado do Rio Grande do Sul. A presença dos primatas e a ocorrência do surto foram registradas por meio de observações diretas e entrevistas. Foram visitadas 11 UC e realizadas 52 entrevistas. Constatou-se que destas UC, três não abrigam primatas, três abrigam populações de Alouatta caraya e quatro de Alouatta guariba. Sapajus nigritus está presente em três UC. A única unidade de conservação severamente impactada pelo surto de FA foi o Parque Estadual do Espigão Alto, embora relatos de óbitos durante o surto tenham sido obtidos para a zona de amortecimento ou entorno próximo de outras cinco UC.

Palavras-chave: Epizootia; Febre Amarela; Primatas Não Humanos; Unidades de Conservação 


\section{Abstract}

Evaluation of the impact of a Yellow Fever outbreak on non-human primate populations in protected areas in Rio Grande do Sul, Brazil. Yellow Fever (YF) is an acute infectious disease. In Brazil, the incidence of YF is seasonal, and frequently occurs between December and April when environmental factors lead to an increase in the abundance of vectors. Several reports about primate mortality due to YF, especially those of the genus Alouatta, have been made, but there is little information that verifies and quantifies how damaging this kind of event is to primate populations. The goal of the present study was to evaluate the impact of a YF outbreak, which occurred in 2008 and 2009, on primate populations in protected areas (PA) in Rio Grande do $\mathrm{Sul}$, the southernmost state of Brazil. The presence of primate species and the occurrence of the outbreak were recorded through direct observation and interviews. We visited 11 PA and made 52 interviews. The presence of Sapajus nigritus and Alouatta caraya was verified in three PA each, and A. guariba in four, while primate populations were absent in three PA. Espigão Alto State Park was the only PA severely impacted by the YF outbreak; however, there were reports of primate deaths during the outbreak in the buffer zones or immediate surroundings of five other PA.

Key words: Epizooty; Non-Human Primates; Protected areas; Yellow fever

\section{Introdução}

O Vírus Amarílico, ou Vírus da Febre Amarela (VFA), sem detecção no Estado do Rio Grande do Sul desde a década de 60, voltou a ser registrado no ano de 2001 em amostras de um exemplar de Alouatta caraya (bugio-preto), mesma época em que foram relatados cerca de 80 óbitos de primatas na região (SALLIS et al., 2003b) e feito o isolamento do vírus em mosquitos silvestres (VASCONCELOS et al., 2003). Posteriormente, no ano de 2002, nova ocorrência do vírus afetou populações de Alouatta guariba no centro do Estado, nos municípios de Jaguari e Mata (TORRES et al., 2003). No verão de 2008/2009, novos surtos de Febre Amarela (FA) ocorreram no centro-sul do Brasil, com maior intensidade nos Estados de São Paulo e Rio Grande do Sul. Neste Estado, a Emergência de Saúde Pública de Importância Nacional (ESPIN) de FA teve início em novembro de 2008, com a morte de primatas no noroeste do Estado, tendo sido confirmados vinte e um casos em humanos (ALMEIDA et al., 2012) e nove óbitos ao longo de sete meses. Entre outubro de 2008 e julho de 2009 foram notificados ao Centro Estadual de Vigilância em Saúde (CEVS) do Rio Grande do Sul 2.013 óbitos de primatas do gênero Alouatta, conhecidos regionalmente por bugios. Em 204 casos, distribuídos em 67 municípios, foi confirmado o VFA como causa morte (ALMEIDA et al., 2012) e o vírus foi isolado em mosquitos de dois municípios do Estado (CARDOSO et al., 2010). O número real de animais mortos pode ter sido muito maior (BICCA-MARQUES; FREITAS, 2010; ALMEIDA et al., 2012). Em julho de 2009, 154 cidades deste Estado estavam em alerta para a FA e quase sete milhões de pessoas necessitavam vacinação contra FA.

A FA é uma doença infecciosa aguda, não contagiosa, de natureza viral, que se mantém endêmica ou enzoótica nas regiões tropicais da América do Sul e Central e da África (MONATH, 1998; MONATH, 2001; VASCONCELOS, 2003). O VFA é um arbovírus africano do gênero Flavivirus (família Flaviviridae). Este flavivírus provavelmente chegou às Américas carreado pelo Aedes aegypti (TRIBE, 1960). O primeiro registro oficial de FA Silvestre no Brasil se deu no Vale do Rio Canaã, Espírito Santo, em 1932 (SOPER et al., 1933). Primatas com evidências sorológicas de infecção por febre amarela foram identificados em dez Estados no Brasil, geralmente nas mesmas regiões onde casos humanos de febre amarela ocorreram (KUMM; LAEMMERT, 1950).

No Brasil, a FA tem caráter sazonal, ocorrendo mais frequentemente entre os meses de dezembro a abril (ROMANO et al., 2011), quando fatores ambientais (tais como maior precipitação e temperatura) propiciam o aumento da abundância dos vetores (VASCONCELOS et al. 2001; VASCONCELOS, 2010). O VFA se mantém por meio de dois ciclos básicos: o urbano e o silvestre. A febre amarela urbana, de cujo ciclo faz parte o mosquito 
Aedes aegypti, teve seu último caso oficialmente registrado no Brasil em 1942 (VASCONCELOS, 2003).

No ciclo silvestre, mais complexo e menos compreendido, a transmissão envolve principalmente primatas não humanos ( $\mathrm{PNH}$ ) e mosquitos diurnos que se reproduzem em cavidades de árvores no dossel (MONATH, 2001). Nesse ciclo, destaca-se a participação dos gêneros Haemagogus e Sabethes na América Latina (VASCONCELOS, 2003).

Os PNH, dado o curto período de viremia durante o qual podem transmitir o vírus para mosquitos, são hospedeiros. Os mosquitos são os reservatórios transmissores do VFA, pois, uma vez infectados, assim permanecem por toda a vida (MONATH, 2001; VASCONCELOS, 2003), havendo comprovação de transmissão vertical (BEATY et al., 1980).

Evidências sugerem que outros animais, como marsupiais arborícolas e roedores, possam ter papel secundário no ciclo de manutenção viral, especialmente em áreas onde os PNH estejam ausentes ou já imunes ao VFA (MONATH, 1998; THOISY et al., 2004).

Em PNH, a viremia dura cerca de três a quatro dias, com a morte podendo ocorrer entre três a sete dias. Os sintomas são: febre, icterícia, apatia, desidratação, anorexia, hemorragia bucal e intestinal, insuficiência hepática e renal, degeneração gordurosa do fígado com necrose extensa e acúmulo de lipídios (BRASIL, 2005). Todos os primatas neotropicais testados em laboratório são susceptíveis ao VFA, contudo, alguns apresentam maior resistência, como os macacos-prego (Sapajus sp.). Os bugios ou guaribas (Alouatta sp.), infectados com doses mínimas do vírus da febre amarela desenvolvem infecção fulminante, comportamento similar aos casos humanos fatais (STRODE, 1951; VASCONCELOS, 2003). Os macacos-prego por sua vez desenvolvem infecção subclínica ou quadro febril fugaz; há viremia, seguida da produção de anticorpos que neutralizam futuras re-infecções (STRODE, 1951; VASCONCELOS, 2003).

Os PNH têm um papel fundamental no controle da FA em humanos, sendo consideradas pelo Ministério da Saúde "sentinelas" em relação à circulação do VFA. A observação de mortes de macacos com suspeita de FA serve como sinalizador para o eventual risco do aparecimento da doença na população humana, possibilitando a adoção de medidas profiláticas (COSTA et al., 2011).

No Rio Grande do Sul, ocorrem duas espécies de bugios, Alouatta guariba clamitans (CABRERA, 1940), o bugio-ruivo, e Alouatta caraya Humboldt, 1812, o bugio-preto, além de uma espécie de macaco-prego, o Sapajus nigritus (Goldfuss, 1809). Os Alouatta são macacos grandes folívoros-frugívoros que formam pequenos grupos, em média seis indivíduos, geralmente com um macho dominante, e que mantém e defendem pequenos territórios (de um a 10 ha) (NEVILLE et al., 1988; GREGORIN et al., 2008). O macaco-prego e o bugio-ruivo estão presentes nos ecossistemas associados à Mata Atlântica, do leste ao centro do Estado. Do centro para o oeste, nas matas ciliares e "capões" de mata do bioma Pampa, encontra-se o bugio-preto. Estes dois bugios são citados na Lista Oficial das Espécies Ameaçadas de Extinção no Rio Grande do Sul (MARQUES et al., 2002).

Há relatos de mortalidades em primatas devido à febre amarela, incluindo aquelas que afetaram bugios, mas muitas vezes o número de animais afetados é incerto (COLLIAS; SOUTHWICK, 1952; ELTON, 1952; VARGAS-MENDEZ; ELTON, 1953; ANDERSON; DOWNS, 1965; BEJARANO, 1979; SOPER, 1979; MENDES, 1989; DÉGALLIER et al., 1992a; 1992b; VASCONCELOS et al., 2001; COLOMBIA, 2002; BRYANT et al., 2003; SALLIS et al., 2003a; RIFAKIS et al., 2006; AGOSTINI et al., 2008; HOLZMANN et al., 2010). No mais recente surto, a partir dos primeiros registros em Misiones, Argentina (HOLZMANN et al., 2010) a propagação do VFA no Rio Grande do Sul tomou sentido oeste-leste, com a detecção de FA em primatas avançando pelo Estado ao ritmo de $100 \mathrm{~km} /$ mês (ALMEIDA et al., 2012). Logo, a mortandade atingiu, num primeiro momento, o bugio-preto e, subsequentemente, as populações do bugio-ruivo.

Há poucas informações que quantifiquem ou expressem a magnitude dos danos causados às populações de primatas neotropicais por eventos desta natureza (OLIVEIRA et al., 2010). Tais informações são essenciais para a elaboração ou revisão de listas 
oficiais de espécies ameaçadas, bem como para subsidiar Análises de Viabilidade Populacional (AVP), e, portanto, são extremamente relevantes para traçar estratégias de manejo preventivo e conservacionista das espécies. $\mathrm{O}$ presente estudo busca avaliar a ocorrência do surto de FA sobre as populações de primatas nas unidades de conservação (UC) do Estado do Rio Grande do Sul.

\section{Material e Métodos}

Para verificar a ocorrência do surto de FA nas UC do Rio Grande do Sul e respectivos entornos, bem como avaliar seu impacto sobre as populações de primatas não humanos, foram visitadas todas as UC minimamente implantadas no Estado, com registro ou ocorrência potencial de primatas, situadas a oeste do meridiano $51^{\circ}$. Este recorte foi definido pelo fato de não haver registros de casos humanos ou número de mortes de primatas a leste deste meridiano que caracterizasse um surto. A primeira expedição foi realizada entre 26 de maio e 2 de junho, a segunda entre 27 de setembro e 1 de outubro de 2010, a terceira entre 4 e 8 de abril de 2011 e a quarta entre 9 e 13 de maio de 2011. Algumas unidades foram visitadas mais de uma vez. Também são apresentadas e discutidas as notificações de epizootias recebidas pela Secretaria Estadual de Saúde (SES) para os municípios abrangidos por estas unidades de conservação.

A presença dos primatas foi registrada por meio de fezes, visualização, vocalização e entrevistas. Por meio de entrevistas também foram obtidas informações sobre fatores associados ao surto de FA, como a intensidade percebida do impacto tanto do recente surto, quanto de surtos históricos. Foi utilizado o método de seleção de informante por grupos de referência (PRINTES et al., 2001; DAVIS; WAGNER, 2003, PRINTES et al., 2011) e entrevistas abertas e semi-estruturadas com residentes do entorno ou da própria unidade. Uma entrevista pode envolver mais de um informante. Também participaram das entrevistas funcionários das UC, agentes de saúde e profissionais da área de extensão rural. As entrevistas seguiram um roteiro semi-estruturado, apoiadas por fotografias e pranchas dos animais, além de vocalizações reproduzidas com equipamento de play-back.
Os resultados do monitoramento e da coleta de amostras de primatas não humanos durante o período de 2008-2009 nos municípios que sediam as UC, obtidos pelo Centro Estadual de Vigilância em Saúde/Secretaria Estadual da Saúde, foram utilizados para afirmar se houve circulação de Febre Amarela entre os primatas em áreas próximas às UC.

\section{Resultados}

Foram visitadas 11 Unidades de Conservação (Figura 1; Tabela 1) e realizadas 52 entrevistas com 62 informantes. Com uma média etária de 48 (27-82) anos, o tempo médio de residência dos mesmos no local, até então, era de 29 (1-81) anos. Mais de três quartos dos informantes foram homens. Constatou-se que destas UC, três não abrigam primatas, três abrigam populações de A. caraya e quatro de $A$. guariba. Sapajus nigritus está presente em três UC. A única unidade de conservação comprovadamente impactada pelo surto de FA foi o Parque Estadual do Espigão Alto. A Tabela 1 resume os principais resultados das expedições.

Todas as três UC, na área de distribuição de $A$. caraya, aparentemente não foram afetadas. Na REBIO de Ibirapuitã, na APA de Ibirapuitã e na REBIO Banhado São Donato não houve relato de morte de $\mathrm{PNH}$ nas entrevistas ou notificações à SES, embora tenham ocorrido registros de epizootias nos municípios a que pertencem. Alegrete apresentou oito notificações (oito óbitos de PNH) e Rosário do Sul uma notificação (um óbito). Itaqui notificou cinco epizootias com seis animais mortos e Maçambará notificou uma epizootia com duas mortes. Nestes municípios não houve animais positivos para o vírus amarílico. Não houve notificação em Santana do Livramento. No Parque Estadual (PE) do Espinilho não há registro de $\mathrm{PNH}$, segundo relatos dos moradores, na área do município de Barra de Quaraí não ocorrem esses animais. As observações de campo sugerem que esta unidade não é adequada para a ocorrência de primatas, visto que as matas estão originalmente restritas as margens dos cursos d'água, entre eles, o rio Uruguai. Em períodos de cheia, grande parte da floresta é encoberta pelas águas. 
FIGURA 1: Unidades de conservação vistoriadas no Estado do Rio Grande do Sul com relação à ocorrência de febre amarela em primatas não humanos. As UC estão numeradas conforme Tabela 1.

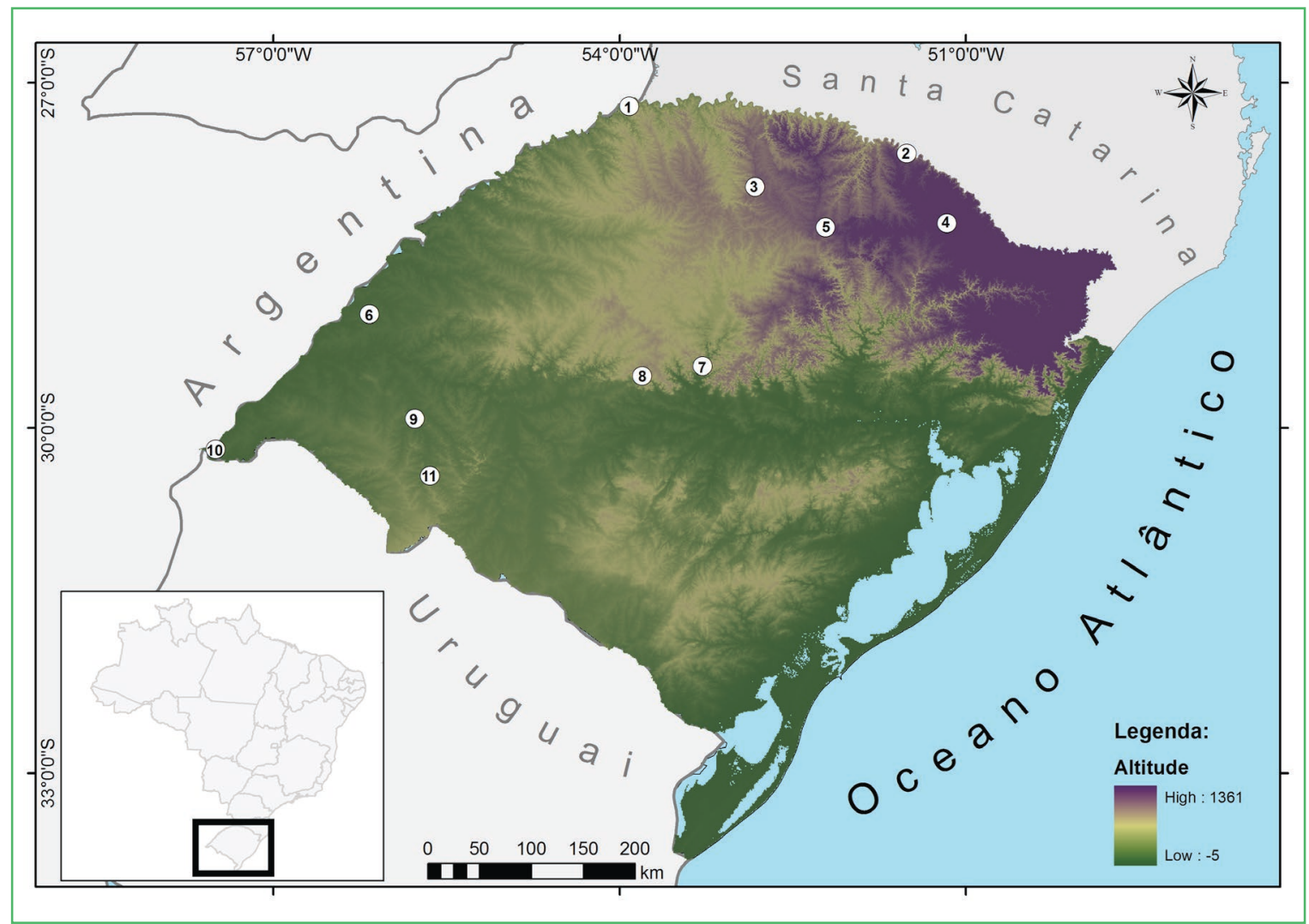

Na área de distribuição de $A$. guariba, três UC não apresentavam a espécie. Na FLONA de Passo Fundo não há nenhuma espécie de primata e nem houve notificação de epizootia na área do município de Mato Castelhano. No PE da Quarta Colônia também não há primatas, mas em seu município (Agudo) foram registradas sete notificações com nove animais mortos, sendo que em três epizootias foram coletadas amostras, resultando em 1 positiva para o vírus amarílico. No $P E$ de Rondinha não houve notificação, embora no município de Sananduva, tenham sido notificadas três epizootias com cinco animais mortos, em um deles foi coletado material, mas o resultado foi negativo.

Das quatro UC com presença de A. guariba, apenas uma foi comprovadamente impactada. O PE de Espigão Alto parece ter sido a UC mais afetada pelo surto de
FA no Estado. A população residente de $A$. guariba foi quase que totalmente, se não por completo, eliminada. O município de Barracão notificou a Secretaria da Saúde do Estado 18 epizootias, somando 30 animais mortos, sendo que foi possível coletar amostra de seis animais, todos positivos para febre amarela. Dos 30 animais mortos, nove estavam dentro da área do Parque, em um deles foi confirmada a Febre Amarela. A equipe de guarda-parques dessa UC observou 22 animais mortos durante o período de surto. Desde então nenhum bugio foi novamente avistado. Os guarda-parques relataram que o número de carcaças de bugios encontradas pode não refletir a magnitude do surto. Como exemplo do tipo de interferência que poderia afetar essa detecção, os entrevistados mencionaram o avistamento de coatis (Nasua nasua) consumindo a carne de bugios mortos. 
TABELA 1: Impacto do surto de febre amarela sobre populações de primatas não humanos nas Unidades de Conservação do Rio Grande do Sul, Brasil.

\begin{tabular}{|c|c|c|c|c|c|c|c|}
\hline & $\begin{array}{l}\text { Unidade de } \\
\text { Conservação }\end{array}$ & Município(s) & Coordenadas & Entrev. & $\begin{array}{l}\text { Espécie(s) } \\
\text { de primata }\end{array}$ & $\begin{array}{l}\text { Surto de } \\
\text { Febre } \\
\text { Amarela } \uparrow \\
\end{array}$ & $\begin{array}{c}\text { Zona de } \\
\text { amortecimento }\end{array}$ \\
\hline 1 & PE do Turvo & Derrubadas & $\begin{array}{l}27^{\circ} 12^{\prime} \mathrm{S} \\
53^{\circ} 55^{\prime} \mathrm{O}\end{array}$ & 2 & $\begin{array}{l}\text { A. guariba, } \\
\text { S. nigritus }\end{array}$ & Não * & $\begin{array}{l}\text { Relatos de } \\
\text { mortes de } \\
\text { Alouatta na } \\
\text { Argentina }\end{array}$ \\
\hline 2 & $\begin{array}{c}\text { PE do Espigão } \\
\text { Alto }\end{array}$ & Barracão & $\begin{array}{l}27^{\circ} 37^{\prime} \mathrm{S} \\
51^{\circ} 31^{\prime} \mathrm{O}\end{array}$ & 2 & $\begin{array}{l}\text { A. guariba, } \\
\text { S. nigritus }\end{array}$ & $\begin{array}{c}\text { Sim } \\
\text { (severa) }\end{array}$ & Sim (severa) \\
\hline 3 & PE de Rondinha & Sananduva & $\begin{array}{l}27^{\circ} 55^{\prime} \mathrm{S} \\
52^{\circ} 50^{\prime} \mathrm{O}\end{array}$ & 1 & S. nigritus & & Não há primatas \\
\hline 4 & ESEC de Aracuri & Muitos Capões & $\begin{array}{l}28^{\circ} 13^{\prime} \mathrm{S} \\
51^{\circ} 10^{\prime} \mathrm{O} \\
\end{array}$ & 3 & A. guariba & Não & Sim (moderada) \\
\hline 5 & $\begin{array}{l}\text { FLONA de Passo } \\
\text { Fundo } \\
\end{array}$ & Mato Castelhano & $\begin{array}{l}28^{\circ} 18^{\prime} \mathrm{S} \\
52^{\circ} 11^{\prime} \mathrm{O} \\
\end{array}$ & 1 & $\begin{array}{l}\text { Não há } \\
\text { primatas }\end{array}$ & & Não há primatas \\
\hline 6 & $\begin{array}{l}\text { REBIO Banhado } \\
\text { São Donato } \\
\end{array}$ & Massambará, Itaqui & $\begin{array}{l}29^{\circ} 01^{\prime} \mathrm{S} \\
56^{\circ} 10^{\prime} \mathrm{O} \\
\end{array}$ & 9 & A. caraya & Não & Não \\
\hline 7 & $\begin{array}{c}\text { PE da Quarta } \\
\text { Colônia }\end{array}$ & Agudo, Ibarana & $\begin{array}{l}29^{\circ} 28^{\prime} \mathrm{S} \\
53^{\circ} 17^{\prime} \mathrm{O}\end{array}$ & 2 & $\begin{array}{l}\text { Não há } \\
\text { primatas }\end{array}$ & & Sim (moderada) \\
\hline 8 & $\begin{array}{l}\text { REBIO do Ibicuí } \\
\text { Mirim } \\
\end{array}$ & $\begin{array}{c}\text { Itaara, } \\
\text { São Martinho da Serra }\end{array}$ & $\begin{array}{l}29^{\circ} 34^{\prime} \mathrm{S} \\
53^{\circ} 48^{\prime} \mathrm{O}\end{array}$ & 12 & A. guariba & Não* & $\begin{array}{c}\text { Sim } \\
\text { (severa) }\end{array}$ \\
\hline 9 & $\begin{array}{c}\text { REBIO de } \\
\text { Ibirapuitã }\end{array}$ & Alegrete & $\begin{array}{l}29^{\circ} 55^{\prime} \mathrm{S} \\
55^{\circ} 47^{\prime} \mathrm{O} \\
\end{array}$ & 5 & A. caraya & Não & Não \\
\hline 10 & PE do Espinilho & Barra do Quarai & $\begin{array}{l}30^{\circ} 11^{\prime} \mathrm{S} \\
57^{\circ} 30^{\prime} \mathrm{O} \\
\end{array}$ & 1 & $\begin{array}{c}\text { Não há } \\
\text { primatas }\end{array}$ & & Não há primatas \\
\hline 11 & APA de Ibirapuitã & $\begin{array}{c}\text { Alegrete, } \\
\text { Santana do Livramento, } \\
\text { Rosário do Sul } \\
\end{array}$ & $\begin{array}{l}30^{\circ} 25^{\prime} \mathrm{S} \\
55^{\circ} 39^{\prime} \mathrm{O}\end{array}$ & 14 & A. caraya & Não & Não \\
\hline
\end{tabular}

$\dagger$ Sugerido pela morte de primatas; * A aparente reduzida densidade pode mascarar o surto.

\section{Discussão}

A FA já foi citada como um dos fatores, dentre outros, como a caça e a degradação de hábitat, que pode promover a redução da densidade populacional e do tamanho dos grupos de Alouatta (COLLIAS; SOUTHWICK, 1952; CROCKETT; EISENBERG, 1987; EISENBERG; REDFORD, 1999). Para Rambo (1956), a ausência ou as reduzidas densidades de Alouatta no planalto médio gaúcho podem ser decorrentes de surtos históricos de FA. Contexto semelhante é apontado por Crespo (1954) para a vizinha província argentina de Misiones. Considerando que atualmente as espécies de primatas no Rio Grande do Sul, como em todo o Brasil, estão sujeitas às diversas interferências antrópicas negativas, as quais levam à redução e ao isolamento populacional, a ocorrência de epizootias letais pode ser determinante para a extinção de populações locais e até mesmo de espécies ao longo de um amplo espaço geográfico, inclusive em áreas protegidas. Embora preocupante, os resultados apontam que o surto ocorrido não foi tão danoso às populações de primatas presentes nas UC do Estado como era esperado.

Em duas UC, REBIO Ibicuí-Mirim e PE do Turvo, as baixas densidades de A. guariba (FIALHO, 2007) não permitem afirmar se houve impactos do surto sobre as populações dessa espécie. Os relatos de observações de indivíduos solitários e a ausência de animais mortos na REBIO Ibicuí-Mirim sugerem que o surto não tenha ocorrido ou não tenha sido tão severo quanto no $\mathrm{PE}$ Espigão Alto. Porém, a oito quilômetros "serra abaixo" desta REBIO, na localidade de Campinas, município 
de São Martinho da Serra (29³3'47'S 5354'14”O) todos os grupos de bugios conhecidos pelos moradores locais desapareceram durante o período de surto, provavelmente devido à FA. Ainda em Campinas, um informante de 76 anos, natural da localidade, relatou ter presenciado dois surtos de FA, o de 1964-66 e o de 2008-2009. Segundo esse senhor, a julgar pelas vocalizações e visualizações eventuais, os surtos reduziram drasticamente as populações de bugios, mas, em relação ao primeiro evento, as populações de primatas se recuperaram ao longo do tempo. Embora em São Martinho da Serra e em Itaara não tenha ocorrido nenhuma notificação de epizootia, nos municípios limítrofes foram registrados vários animais positivos para FA. O motivo da ausência de notificação pode estar associado a falhas na Vigilância dos Municípios ou a não circulação viral, faltam investigações para determinar as causas reais destes fatos. No PE do Turvo dois relatos de guarda-parques, um de avistamento recente de um grupo e outro de vocalização, ocorridos após o período de surto, bem como a ausência do registro de animais mortos, sugerem que aquela unidade de conservação não tenha sido afetada. Embora, haja relatos indicando que um indivíduo de Alouatta teria sido encontrado morto em setembro de 2010 em uma comunidade fronteiriça argentina.

Em Muitos Capões, município da Estação Ecológica (ESEC) de Aracuri, houve nove notificações de mortes de bugios, totalizando 20 animais mortos. Foi possível coletar amostras de quatro animais, sendo três positivos para febre amarela, mas sem notificações na área da Unidade. Segundo os informantes selecionados, muitos grupos sociais desapareceram nesta localidade. Todavia, curiosamente não foi registrado um único óbito de Alouatta na unidade de conservação e animais foram avistados durante vistoria realizada em 28 de setembro de 2010.

Para as unidades ESEC de Aracuri e REBIO de Ibicuí-Mirim, foram relatados óbitos exclusivamente nos seus entornos. Ambas têm em comum a ausência de gado em seu interior. Já no PE de Espigão Alto, que possui fisionomia florestal e comunidade faunística muito semelhante à da ESEC de Aracuri, mas onde há presença de gado, o surto foi severo. Na Nigéria, Adu et al. (1990) apontam evidências da presença de anticorpos para o VFA em herbívoros domésticos, portanto, seria interessante a investigação desta hipótese no presente contexto, dado o manejo itinerante a que os rebanhos são submetidos.

Em nenhuma localidade foi relatada a morte de Sapajus potencialmente por FA. Já relatos não confirmados de óbitos provocados (por lapidação, disparos e envenenamento) de Sapajus e Alouatta, foram recorrentes. É possível que o temor do contágio por FA tenha motivado estas agressões, no entanto, tratandose de crime ambiental, as informações a respeito são imprecisas e questionáveis.

O PE do Espigão Alto apresentou uma redução extrema, senão extinção, de sua população de $A$. guariba. Entretanto, outras UC não foram afetadas. Isto sugere que modelagens devem prever, no caso de FA, ou epizootias semelhantes, diferentes intensidades de resposta ao longo de um espaço geográfico, com picos de respostas negativas como extinções regionais.

\section{Agradecimentos}

Agradecemos às equipes das Unidades de Conservação gerenciadas pelo ICMBIo e pela Secretaria do Meio Ambiente do Estado do Rio Grande do Sul (SEMA-RS) e, as professoras Valeska Martins da Silva e Thais Leiroz Codenotti.

\section{Referências}

ADU, F.; ESAN, J.; BABA, S. S. Seroepidemiological survey for yellow fever antibodies in domestic animals. Revue Roumaine de Virologie, Bucuresti, v. 41, n. 3-4, p. 147-150, 1990.

AGOSTINI, I.; HOLZMANN, I.; DI BITETTI M. S. Infant hybrids in a newly formed mixed-species group of howler monkeys (Alouatta guariba clamitans and Alouatta caraya) in northeastern Argentina. Primates, Inuyama, v. 49, p. 304-307, 2008.

ALMEIDA, M. A. B.; SANTOS, E.; CARDOSO, J. C.; FONSECA, D. F.; NOLL, C. A.; SILVEIRA, V. R.; MAEDA, A. Y.; SOUZA, R. P.; KANAMURA, C.; BRASIL, R. A. Yellow fever outbreak affecting Alouatta populations in southern Brazil (Rio Grande do Sul State), 2008-2009. American Journal of Primatology, New York, v. 74, n. 1, p. 68-76, 2012.

ANDERSON, C. R.; DOWNS, W. G. The isolation of yellow fever virus from the livers of naturally infected red howlers monkeys. Caribbean Medical Journal, West Indies, v. 27, n. 1-4, p. 75-77, 1965. 
BEATY, B. J.; TESH, R. B.; AITKEN, T. H. Transovarial transmission of yellow fever virus in Stegomyia mosquitoes. The American Journal of Tropical Medicine and Hygiene, Deerfield, v. 29 , n. 1 , p. $125-132,1980$

BEJARANO, J. F. Estudio sobre Fiebre Amarilla Selvatica en la Republica Argentina. Buenos Aires: Ministerio de Bienestar Social de la Nacion/Secretaria de Estado de Salud Publica, 1979. 38 p. v. 64

BICCA-MARQUES, J. C.; FREITAS, D. S. The role of monkeys, mosquitoes and humans in the occurrence of a yellow fever outbreak in a fragmented landscape in south Brazil: protecting howler monkeys is a matter of public health. Tropical Conservation Science, Menlo Park, v. 3, n. 1, p. 78-89, 2010.

BRASIL. Manual de vigilância de epizootias em primatas nãohumanos. Brasília: Ministério da Saúde/FUNASA, 2005. 56 p.

BRYANT, J.; WANG, H.; CABEZAS, C.; RAMIREZ, G.; WATTS, D.; RUSSEL, K.; BARRETT, A. Enzootic transmission of yellow fever virus in Peru. Emerging Infectious Diseases, Atlanta, GA, v. 9, n. 8, p. 926-933, ago. 2003.

CARDOSO, J. C.; ALMEIDA, M. A. B.; SANTOS, E.; FONSECA, D. F.; SALLUM, M. A. M.; NOLL, C. A.; MONTEIRO, H. A. O.; CRUZ, A. C. R.; CARVALHO, V. L.; PINTO, E. V.; CASTRO, F. C.; NUNES NETO, J. P.; SEGURA, M. N. O.; VASCONCELOS, P. F. C.. Yellow fever virus in Haemagogus leucelaenus and Aedes serratus mosquitoes, southern Brazil, 2008. Emerging Infectious Diseases, Atlanta, v. 16, n, 12, p. 1918-1924, 2010.

COLLIAS, N. E.; SOUTHWICK, C. H. A field study of the population density and social organization in howler monkeys. Proceedings of the American Philosophical Society, Philadelphia, v. 96, n. 2, p. 144-156, 1952.

COLOMBIA. Ministerio de Salud. Instituto Nacional de Salud. Investigación de campo casos de fiebre amarilla, municipio de Mani, Departamento de Casanare. OPS-OMS. Boletin epidemiológico semanal do SIVIGILA, Bogotá, n. 34, 2002. Disponível em: $<$ http://www.col.ops-oms.org/sivigila/2002/BOLE34 02.htm>. Acesso em: 27 jul. 2010.

COSTA, Z. G. A.; ROMANO, A. P. M.; ELKHOURY, A. N. M.; FLANNERY, B. Evolução histórica da vigilancia epidemiológica e do controle da febre amarela no Brasil. Revista Pan-Amazônica de Saúde, Ananindeua, v. 2, n. 1, p. 11-26, 2011

CRESPO, J. A. Presence of reddish howling monkey (Alouatta guariba clamitans Cabrera) in Argentina. Journal of Mammalogy, Lawrence, v. 35, p. 177-118, 1954.

CROCKETT, C. M.; EISENBERG, J. F. Howlers: variations in group size and demography. In: SMUTS, B. B.; CHENEY, D. L.; SEYFARTH, R. M.; WR, R. W. (Ed.). Primate Societies. Chicago: University of Chicago Press, 1987. p. 54-68.

DAVIS, A.; WAGNER, J. R. Who knows? On the importance of identifying "experts" when researching Local Ecological Knowledge. Human Ecology, New York, v. 31 n. 3, p. 463-489, 2003.

DÉGALLIER, N.; ROSA, A. P. A. T.; HERVE, J. P.; ROSA, J. F. S. T.; VASCONCELOS, P. F. C.; SILVA, C. J. M.; BARROS, V. R. S.; DIAS, L. B.; ROSA, E. S. T.; RODRIGUÊS, S. G. A comparative study of yellow fever in Africa and South America. Journal of the Brazilian Association for the Advancement of Science, Rio de Janeiro, v. 44, n. 2-3, p. 143-161, 1992 b.
DÉGALliER, N.; ROSA, A. P. A. T.; VASCONCELOS, P. F. C.; ROSA, E. S. T.; RODRIGUES, S. G.; SÁ FILHO, G. C.; ROSA, J. F. S. T. New entomological and virological data on the vectors of sylvatic yellow fever in Brazil. Journal of the Brazilian Association for the Advancement of Science, Rio de Janeiro, v. 44, n. 2-3, p. 136-142, 1992a.

EISENBERG, J. F.; REDFORD, K. H. Mammals of the neotropics: the central neotropics. v. 3. Chicago: University of Chicago Press. 1999. $609 \mathrm{p}$.

ELTON, N. W. Progress of sylvan yellow fever wave in Central América: Nicarágua and Honduras. American Journal of Public Health, Bethesda, v. 42, n. 12, p. 1527-1534, 1952.

FIALHO, M. S. Riqueza e abundância da fauna de médio e grande porte em três modelos de áreas protegidas no sul do Brasil. 2007. 118 f. Tese (Doutorado em Ecologia) - Universidade Estadual de Campinas, Campinas. 2007

GREGORIN, R.; KUGELMEIER, T.; VALLE, R. R. Gênero Alouatta. In: REIS, N. R.; PERACCHI, A. L.; ANDRADE, F. R. (Ed.). Primatas brasileiros. Londrina: Technical Books, 2008. p. 189-204.

HOLZMANN, I.; AGOSTINI, I.; ARETA, J. I.; FERREYRA, H.; BELDOMENICO, P.; DI BITETTI, M. S. Impact of yellow fever outbreaks on two howler monkey species (Alouatta guariba clamitans and A. caraya) in Misiones, Argentina. American Journal of Primatology, New York, v. 72, n. 6, p. 475-480, 2010. KUMM, H. W.; LAEMMERT, H. W. The geographical distribution of immunity to yellow fever among the primates of Brazil. The American Journal of Tropical Medicine and Hygiene, Deerfield, v. 30, n. 1, p. 733-748, set. 1950.

MARQUES, A. A. B.; FONTANA, C. S.; VÉLEZ, E.; BENCKE, G. A.; SCHNEIDER M.; REIS, R. E. (Org.). Lista das espécies da fauna ameaçadas de extinção no Rio Grande do Sul. Decreto nº 41.672, de 11 de junho de 2002. Porto Alegre: FZB/MCTPUCRS/ PANGEA, 2002. $52 \mathrm{p}$.

MENDES, S. L. Estudo ecológico de Alouatta fusca (Primates: Cebidae) na Estação Biológica de Caratinga, MG. Revista Nordestina Biologia, João Pessoa, v. 6, n. 2, p. 71-104, 1989.

MONATH, T. P. Yellow fever. In: PALMER, S. R.; SOULSBY, L.; SIMPSON, D. I. H. (Ed.). Zoonoses. Oxford: University Press, 1998. p. 487-498.

MONATH, T. P. Yellow fever: An update. Lancet Infectious Diseases, Solna, v. 1, n. 1, p. 11-20, 2001

NEVILLE, M. K.; GLANDER, K. E.; BRAZA, F.; RYLANDS, A. B. The howling monkeys, genus Alouatta. In: RUSSELL A.; RYLANDS, A. B.; COIMBRA-FILHO, A.; FONSECA, G. A. B.; MITTERMEIER A. R. (Ed.). Ecology and Behavior of Neotropical Primates. v. 2. Washington: World Wildlife Fund, 1988. p. 349-453

OLIVEIRA, S. V.; BAIRROS, S.; LOPES, J. T. S. Vigilância da febre amarela em Caçapava do Sul, Rio Grande do Sul. Revista Pan-Amazônica de Saúde, Ananindeua, v. 1, n. 1, p. 181-186, 2010

PRINTES, R. C.; LISENFIELD, M. V. A.; JERUSALINSKY, L. Alouatta guariba clamitans Cabrera, 1940: A new southern limit for the species and for Neotropical primates. Neotropical Primates, Arlington, v. 9, n. 3, p. 18-121, 2001. 
PRINTES, R. C.; RYLANDS, A. B.; BICCA-MARQUES, J. C. Distribution and status of the critically endangered blond titi monkey Callicebus barbarabrownae of north-east Brazil. Oryx, Cambridge, v. 45, n. 3, p. 439-443, 2011.

RAMBO, B. A fisionomia do Rio Grande do Sul. Porto Alegre: Livraria Selbach, 1956. 39 p.

RIFAKIS, P. M.; BENITEZ, J. A.; DE-LA-PAZ-PINEDA, J.; RODRIGUES-MORALES, A. J. Epizootics of Yellow Fever in Venezuela (2004-2005): an emerging zoonotic disease. Annals of the New York Academy of Sciences, New York, v. 1081, p. 57-60, 2006.

ROMANO, A. P. M.; RAMOS, D. G.; ARAÚJO, F. A. A.; SIQUEIRA, G. A. M.; RIBEIRO, M. P. D.; LEAL, S. G.; ELKHOURY, A. N. M. S. Febre Amarela no Brasil: recomendações para a vigilância, prevenção e controle. Epidemiologia e Serviços de Saúde, Brasília, v. 20, n. 1, p. 101-106, 2011.

SALLIS E. S. V.; BARROS, V. L. R.; GARMATZ, S. L.; FIGHERA, R. A.; GRAÇA, D. L. A case of yellow fever in a brown howler monkey (Alouatta fusca) in southern Brazil. Journal of Veterinary Diagnostic Investigation, Columbia, v. 15, n. 6, p. 547-576, 2003a

SALLIS, E. S. V.; GARMATZ, S. L.; FIGHERA, R. A.; BARROS, V. L. R. S.; GRAÇA, D. L. Surto de febre amarela em bugios. Acta Scientiae Veterinariae, Porto Alegre, v. 31, n. 2, p. 115-117, 2003b.

SOPER, F. L. Andanzas por el mundo de la salud: memórias de Fred Lowe Soper. Editado por John Duffy. Washington: Organización Panamericana de la Salud/Organización Mundial de la Salud, 1979. 387 p.

SOPER, F. L; PENNA, H.; CARDOSO, E.; SERAFIM Jr., J.; FROBISHER Jr., M.; PINHEIRO, J. Yellow Fever without Aedes aegypti: study of a rural epidemic in the Valle do Chanaan, Espírito Santo, Brazil, 1932. American Journal of Epidemiology, Oxford v. 18, n. 3 , p. 555-586, 1933.

STRODE, G. K. Yellow fever. New York: McGraw-Hill, 1951. 725 p.
THOISY, B; DUSSART, P; KAZANJI, M. Wild terrestrial rainforest mammals as potential reservoirs for flaviviruses (yellow fever, dengue 2 and St Louis encephalitis viruses) in French Guiana. Transactions of the Royal Society of Tropical Medicine and Hygiene, London, v. 98, n. 7, p. 409-412, 2004.

TORRES, M. A. N.; SANTOS, E.; ALMEIDA, M. A. B.; CRUZ, L. L.; SPERB, A. F. Vigilância da Febre Amarela Silvestre no Rio Grande do Sul. Boletim Epidemiológico. Porto Alegre: Secretaria da Saúde do Rio Grande do Sul, v. 5, p. 1-8, 2003.

TRIBE, G. W. Simian haemorrhagic fever in perspective. Primates, Inuyama, v. 2, n. 3, Suplemento, p. 40-41, 1960.

VARGAS-MENDEZ, O.; ELTON, N. W. Naturally acquired yellow fever in wild monkeys of Costa Rica. The American Journal of Tropical Medicine and Hygiene, Deerfield, v. 2, n. 5, p. 850-863, 1953.

VASCONCELOS, P. F. C. Febre amarela. Revista da Sociedade Brasileira de Medicina Tropical, Uberaba, v. 36, n. 2, p. 275-293, 2003.

VASCONCELOS, P. F. C. Yellow Fever in Brazil: thoughts and hypotheses on the emergence in previously free areas. Revista de Saúde Pública, São Paulo, v. 44 n. 6, p. 1144-1149, 2010.

VASCONCELOS, P. F. C; COSTA, Z. G.; ROSA, E. S. T.; LUNA, E.; RODRIGUES, S. G.; BARROS, V. L. R. S.; DIAS, J. P.; MONTEIRO, H. A. O.; OLIVA, O. F. P.; VASCONCELOS, H. B.; OLIVEIRA, R. C.; SOUSA, M. R. S.; SILVA, J. B.; CRUZ, A. C. R.; MARTINS, E. C.; ROSA, J. F. S. T. Epidemic of jungle yellow fever in Brazil, 2000: Implications of climatic alterations in disease spread. Journal of Medical Virology, New York, v. 65, n. 3, p. 598-604, 2001.

VASCONCELOS, P. F. C.; SPERB, A. F.; MONTEIRO, H. A. O.; TORRES, M. A. N.; SOUSA, M. R. S.; VASCONCELOS, H. B.; MARDINI, L. B. L. F.; RODRIGUES, S. G. Isolations of yellow fever virus from Haemagogus leucocelaenus in Rio Grande do Sul State, Brazil. Transactions of the Royal Society of Tropical Medicine and Hygiene, London, v. 97, n. 1, p. 60-62, 2003. 